Gut, 1979, 20, 565-567

\title{
Effects of lysine vasopressin and glypressin on the fibrinolytic system in cirrhosis
}

\author{
J. G. DOUGlaS ${ }^{1}$, J. A. H. FORREST, C. V. PROWSE, J. D. CASH, AND \\ N. D. C. FINLAYSON \\ From the Gastrointestinal and Liver Service, and the Regional Blood Transfusion Centre, Royal Infirmary, \\ Edinburgh
}

SUMMARY In eight patients with cirrhosis of the liver and portal hypertension an intravenous infusion of lysine vasopressin induced a rapid increase in the plasma level of the fibrinolytic proenzyme plasminogen activator. In contrast, triglycyl lysine vasopressin (glypressin; GVP), in a dose known to lower portal venous pressure, produced no fibrinolytic response. This lack of fibrinolytic response represents an advantage of GVP over lysine vasopressin in addition to its longer in vivo halflife and lower cardiotoxicity. Clinical trials of GVP in the treatment of bleeding oesophageal varices are needed.

Lysine vasopressin is the standard drug used to treat bleeding oesophageal varices. Its disadvantages include a short half-life, tachyphylaxis, cardiotoxicity and, in normal subjects, it stimulates the systemic release of the fibrinolytic proenzyme plasminogen activator (Gader et al., 1973b). Although the recently developed triglycyl form of lysine vasopressin (glypressin; GVP) does not increase the systemic release of plasminogen activator in normal subjects (Cash et al., 1978), there is no information of its effect in cirrhosis, in which there may be raised levels of this substance and where excessive responses to physiological and pharmacological stimuli may occur (Das and Cash, 1969; Gader et al., 1973a; Robertson, 1971).

We describe the fibrinolytic response to intravenous lysine vasopressin and GVP in cirrhotic patients with portal hypertension. GVP has a lower cardiotoxicity and a long in vivo half-life (Aronsen $e t$ al., 1975; Vosmik et al., 1977) than lysine vasopressin and, if it produced no rise in plasminogen activator in cirrhosis, it would have potential advantages in the control of bleeding oesophageal varices.

\section{Methods}

PATIENTS

The clinical and laboratory details of the patients

${ }^{1}$ Address for correspondence: J. G. Douglas, Gastrointestinal and Liver Service, Royal Infirmary, Edinburgh.

Received for publication 13 February 1979 studied are shown in Table 1. Patients 1-3 were deemed to have mild liver disease (albumin and vitamin $\mathrm{K}$ corrected prothrombin time ratio normal) and patients 4-8 severe liver disease (albumin and prothrombin time ratio abnormal). All but patient 2 had had ascites, and patient 5 had also had encephalopathy. In six patients the diagnosis was confirmed by liver biopsy. Two patients did not undergo liver biopsy; one because of severe lung disease and the other because of the abnormal PTR and thrombocytopenia. Both these patients had clinical and biochemical evidence of chronic liver disease and liver scans compatible with cirrhosis. All eight patients had portal hypertension, as evidenced by oesophageal varices on barium swallow. None was bleeding at the time of the studies.

Eight patients were infused with $10 \mu \mathrm{g}$ lysine vasopressin, five with $750 \mu \mathrm{g}$ GVP (a dose used previously in normal subjects (Cash et al., 1978)), and eight with $2000 \mu \mathrm{g}$ GVP. All patients gave their informed consent. The infusions were carried out between 9 a.m. and 11 a.m. at intervals of at least a week. All studies were performed in a similar manner. After a 15 minute rest period $50 \mathrm{ml}$ saline were infused into a cubital fossa vein over 15 minutes via a 19 gauge butterfly needle with a Harvard constant infusion pump. The vasopressin, dissolved in $50 \mathrm{ml}$ saline, was then infused over a 15 minute period. Pulse rate and blood pressure were measured at 15 minute intervals before and for $\mathbf{7 5}$ minutes after the vasopressin infusion. An electrocardiogram was taken before, every two minutes during each infusion, 
Table 1 Clinical and laboratory details of eight cirrhotic patients

\begin{tabular}{|c|c|c|c|c|c|c|c|}
\hline $\begin{array}{l}\text { Patient } \\
\text { no. }\end{array}$ & $\begin{array}{l}\text { Age } \\
(y r)\end{array}$ & Sex & $\begin{array}{l}\text { Bilirubin }(\mu \mathrm{mol} / \mathrm{l}) \\
(3-17)\end{array}$ & $\begin{array}{l}\text { Alanine } \\
\text { aminotransferase } \\
\text { (units/l) } \\
(10-40)\end{array}$ & $\begin{array}{l}\text { Alkaline phosphatase } \\
\text { (units/l) } \\
(15-100)\end{array}$ & $\underset{(36-45)}{\operatorname{Albumin}(g / l)}$ & $\begin{array}{l}\text { Prothrombin time ratio } \\
(<1 \cdot 3)\end{array}$ \\
\hline 1 & 55 & $\mathbf{M}$ & 9 & 18 & 75 & 43 & $1 \cdot 0$ \\
\hline 2 & 49 & $\mathbf{M}$ & 27 & 47 & 137 & 41 & $1 \cdot 1$ \\
\hline 3 & 68 & $\mathbf{M}$ & 22 & 52 & 68 & 46 & $1 \cdot 2$ \\
\hline 4 & 58 & $\mathbf{M}$ & 47 & 47 & 120 & 25 & $1 \cdot 6$ \\
\hline 5 & 49 & $\mathbf{M}$ & 51 & 27 & 177 & 27 & $1 \cdot 8$ \\
\hline 6 & 54 & $\mathbf{F}$ & 83 & 28 & 230 & 33 & $1 \cdot 9$ \\
\hline 7 & 48 & $\mathbf{M}$ & 29 & 22 & 116 & 33 & $1 \cdot 4$ \\
\hline 8 & 63 & $\mathbf{M}$ & 47 & 21 & 198 & 31 & $1 \cdot 6$ \\
\hline
\end{tabular}

* Normal ranges in parentheses.

and at 15 and 45 minutes after the infusion. Serial blood samples were obtained either through an indwelling needle, or by separate venepuncture.

\section{TECHNIQUES}

The plasma plasminogen activator content was assessed by the euglobulin lysis time and unheated human fibrin plate techniques (Cash, 1966). Latex agglutination methods were used to measure serum fibrin degradation products (Thrombo-Wellcotest; Wellcome Reagents Limited, England) and plasminantiplasmin complexes (Collen et al., 1977).

Statistical analysis was by Student's paired $t$ test.

\section{Results}

\section{PLASMINOGEN ACTIVATOR}

All five patients with severe liver disease had resting levels of plasminogen activator significantly above those previously found in normal subjects, those with mild liver disease having levels within the normal range (Table 2). The pre-infusion plasminogen activator levels correlated significantly with the plasma albumin concentration $(r=0.91 ; \mathrm{P}=$ $<0.01)$ and the prothrombin time ratio $(r=0.81$;
$P=<0.05)$, but not with the plasma bilirubin concentration, alanine aminotransferase, or alkaline phosphatase activities. After infusion with lysine vasopressin, two of those with mild liver disease and all five patients with severe liver disease had rapid rises in plasminogen activator above the normal range. Although the levels after lysine vasopressin in those with severe liver disease were much higher than those with mild liver disease, the former did not have a greater percentage rise over pre-infusion levels than the latter or normal subjects. As in normal subjects, the plasminogen activator levels in the cirrhotic patients returned to pre-infusion levels 60 minutes after the end of the infusion. In contrast, both 750 $\mu \mathrm{g}$ and $2000 \mu \mathrm{g}$ of GVP produced no change in the plasminogen activator. The results using the unheated fibrin plate technique confirmed the results of the euglobulin lysis time method. Pre-infusion levels of fibrin degradation products and plasmin-antiplasmin complexes were normal and there was no change after lysine vasopressin or GVP.

\section{CLINICAL EFFECTS}

During lysine vasopressin and GVP infusions there was a significant, but clinically unimportant, fall in

Table 2 Plasminogen activator levels (as euglobulin lysis time units) in eight cirrhotic patients before and after infusion of $10 \mu \mathrm{g}$ lysine vasopressin

\begin{tabular}{|c|c|c|c|c|c|c|}
\hline \multirow{2}{*}{$\begin{array}{l}\text { Patient } \\
\text { no. }\end{array}$} & \multicolumn{5}{|l|}{ Minutes } & \multirow{2}{*}{$\begin{array}{l}\text { Baseline values } \\
\text { before } 20 \mathrm{CO} \mu \mathrm{g} \\
\text { GVP }\end{array}$} \\
\hline & 0 & 15 & 30 & 60 & 90 & \\
\hline 1 & $9 \cdot 4$ & $4 \cdot 9$ & $54 \cdot 2$ & $22 \cdot 4$ & $13 \cdot 8$ & $5 \cdot 0$ \\
\hline 2 & $13 \cdot 0$ & $11 \cdot 1$ & $27 \cdot 7$ & $14 \cdot 6$ & $16 \cdot 3$ & $3 \cdot 6$ \\
\hline 3 & $8 \cdot 7$ & 5.6 & $36 \cdot 1$ & $18 \cdot 6$ & 6.8 & $6 \cdot 1$ \\
\hline 4 & $93 \cdot 0$ & $62 \cdot 0$ & $118 \cdot 0$ & $100 \cdot \mathrm{C}$ & $72 \cdot 0$ & $59 \cdot 1$ \\
\hline 5 & $52 \cdot 0$ & $52 \cdot 0$ & $108 \cdot 3$ & 52.0 & $23 \cdot 6$ & $59 \cdot 1$ \\
\hline 6 & $76 \cdot 5$ & $46 \cdot 4$ & $108 \cdot 0$ & $65 \cdot 0$ & $46 \cdot 4$ & $37 \cdot 1$ \\
\hline 7 & $43 \cdot 3$ & $39 \cdot 4$ & $76 \cdot 5$ & $43 \cdot 3$ & $29 \cdot 6$ & $26 \cdot 0$ \\
\hline 8 & $21 \cdot 7$ & 20.6 & $52 \cdot 0$ & $32 \cdot 5$ & $25 \cdot 0$ & $43 \cdot 3$ \\
\hline \multirow{2}{*}{$\begin{array}{l}\text { Range for normal subjects } \\
(n=5)\end{array}$} & & & & & & \\
\hline & $4 \cdot 4-13 \cdot 8$ & $5 \cdot 5-12 \cdot 6$ & $20 \cdot 0-34 \cdot 9$ & $10 \cdot 0-24 \cdot 5$ & $8 \cdot 0-18 \cdot 7$ & - \\
\hline
\end{tabular}

The drug was infused from the fifteenth to the thirtieth minute.

GVP infusions induced no change in euglobulin lysis time, though similar pre-infusion values were seen. 
the pulse rate and rise in blood pressure which returned to pre-infusion levels within 15 minutes after the infusion. No ECG changes were noted. Facial pallor was seen during all infusions, persisting longer with glypressin. Lysine vasopressin produced abdominal colic in six of eight patients, $750 \mu \mathrm{g}$ glypressin in one of five patients and $2000 \mu \mathrm{g}$ glypressin in four of eight patients.

\section{Discussion}

In patients bleeding from oesophageal varices, lysine vasopressin is used to reduce portal venous pressure in the hope that this will help stop bleeding. Tachyphylaxis and cardiotoxicity are well recognised problems associated with the use of lysine vasopressin and its ability to increase plasma plasminogen activator may constitute a further less well-recognised difficulty. Although lysine vasopressin did not produce frank fibrinolysis, as evidenced by a lack of increase in fibrin degradation products in the cirrhotic patients, the increased plasma plasminogen activator levels could lead to the lysis of fibrin deposited at the site of variceal bleeding. This might be of great importance in patients with more severe liver disease whose already raised plasma plasminogen activator levels are further increased.

In contrast, GVP, in doses which will lower portal venous pressure (Vosmík et al., 1977), did not increase the plasma levels of plasminogen activator. In addition, GVP has the advantages of a longer in vivo half-life and less cardiotoxicity than lysine vasopressin. Although the mode of action of GVP is uncertain, it probably acts as a depot from which lysine vasopressin is slowly released into the circulation. As GVP may have significant advantages over lysine vasopressin in the treatment of bleeding oesophageal varices, clinical trials would seem indicated to establish its therapeutic efficacy.

Dr D. Collen (Leuven, Belgium) kindly supplied the plasmin-antiplasmin reagent.

\section{References}

Aronsen, K. F., Wetterlin, S., Emås, S., Vojtišek, V., Mulder, J. L., and Cort, J. H. (1975). Die Wirkung von TriglycylLysin-Vasopressin auf Kontrollpersonen und Patienten mit Blutungen des oberen Gastrointestinaltraktes. Klinische Wochenschrift, 53, 747-753.

Cash, J. D. (1966). Effect of moderate exercise on the fibrinolytic system in normal young men and women. British Medical Journal, 2, 502-506.

Cash, J. D., Gader, A. M. A., Mulder, J. L., and Cort, J. H. (1978). Structure-activity relations of the fibrinolytic response to vasopressins in man. Clinical Science and Molecular Medicine, 54, 403-409.

Collen, D., De Cock, F., Cambiaso, C. L., and Masson, P. (1977). A latex agglutination test for the rapid quantitative estimation of the plasmin-antiplasmin complex in human plasma. European Journal of Clinical Investigation, 7, 21-26.

Das, P. C., and Cash, J. D. (1969). Fibrinolysis at rest and after exercise in hepatic cirrhosis. British Journal of Haematology, 17, 431-443.

Gader, A. M. A., Anderton, J. L., and Cash, J. D. (1973a). The fibrinolytic response to venous occlusion in hypoproteinaemic patients. Thrombosis Research, 3, 219-229.

Gader, A. M. A., Da Costa, J., and Cash, J. D. (1973b). A new vasopressin analogue and fibrinolysis. Lancet, 2, 14171418.

Robertson, B. R. (1971). Effect of nicotinic acid on fibrinolytic activity in health, in thrombotic disease and in liver cirrhosis. Acta Chirurgica Scandinavia, 137, 643-648.

Vosmík, J., Jedlička, K., Mulder, J. L., and Cort, J. H. (1977). Action of the triglycyl hormonogen form of vasopressin (glypressin) in patients with liver cirrhosis and bleeding esophageal varices. Gastroenterology, 72, 605-609. 